\title{
Ecologia urbana: conceitos, pré-conceitos e pós-conceitos
}

\author{
Urban ecology: Concepts, preconcepts and postconcepts
}

\author{
James Miyamoto* Gilda Collet Bruna**
}

*Professor-Associado da Faculdade de Arquitetura e Urbanismo, Universidade Federal do Rio de Janeiro (FAUUFRJ), onde leciona desde 1993, com vínculo com o Departamento de Análise e Representação da Forma (DARF) do qual foi Chefe de Departamento (2014-2016). Professor da Graduação da FAU-UFRJ e do Programa de Pós-Graduação em Urbanismo (PROURB-FAU-UFRJ).

Foi representante dos Professores-Associados da FAUUFRJ. Atualmente, é Diretor Adjunto de Extensão da FAUUFRJ.
**Professora Associada Pleno da Universidade Presbiteriana Mackenzie, tendo sido Coordenadora do Programa de Pós-Graduação em Arquitetura e Urbanismo (2004-2008) Foi Diretora da Faculdade de Arquitetura e Urbanismo da Universidade de São Paulo (FAUUSP, 1991-1994). Aposentou-se como Professora Titular da FAUUSP. Livredocente FAUUSP (1980) Doutorado FAUUSP (1972). Graduação FAUUSP (1968). Foi professora visitante na Universidade do Novo México (1985). Foi Coordenadora do Curso de Arquitetura e Urbanismo da Universidade de Mogi das Cruzes.

\section{Resumo}

A realidade torna-se cada vez mais complexa, a partir da multidisciplinaridade crescente e dos enredamentos extremos, em um mundo predominantemente urbano, no qual já existem quase três dezenas de cidades com mais de 10 milhões de habitantes. Hoje, cerca de $54 \%$ da população vive em cidades, no contexto mundial de, aproximadamente, 7,5 bilhões de pessoas. As cidades devem ser vistas como entidades ecológicas, com forte predominância da ação antrópica. Aliás, muitos cientistas afirmam que, provavelmente, não existe lugar plenamente protegido da influência humana no planeta. A compreensão da distinção entre "ecologia da cidade" e "ecologia na cidade" propiciou visões mais rigorosas e reais do planeta. Os problemas ambientais, biológicos e sociais são muitos e necessitam de análises específicas (ecossistêmicas), alicerçadas em bases teóricas consistentes. O presente trabalho traçará a evolução da expressão "ecologia urbana" e discutirá questões consideradas fundamentais, relacionadas aos conceitos, pré-conceitos e pós-conceitos propostos.

Palavras-chave: Ecossistemas urbanos. Ecologia da cidade. Ecologia na cidade.

\section{Abstract}

The world is becoming more and more complex in a predominantly urban reality, amid increasing multidisciplinary issues and particularly entangled challenges. Today there are already almost thirty cities with more than 10 million inhabitants. Considering a world population of approximately 7.5 billion people, about $54 \%$ of that total live in urban areas.Cities must be seen as ecological entities, with a strong predominance of anthropic action. In fact, many scientists claim that there is probably no place on earth fully protected from human influence. A clear understanding of the distinction between "ecology of the city" and "ecology in the city" provided more rigorous and tangible views of the planet. There are many environmental, biological and social problems and they require specific analyses (ecosystemic) structured within a reliable theoretical basis. The present work will trace the evolution of the expression "urban ecology" and will discuss topics, from various approaches and different points of view related to the proposed ideas of concepts, preconcepts and postconcepts.

Keywords: Urban ecosystems. Ecology from the city. Ecology in the city. 


\section{Introdução}

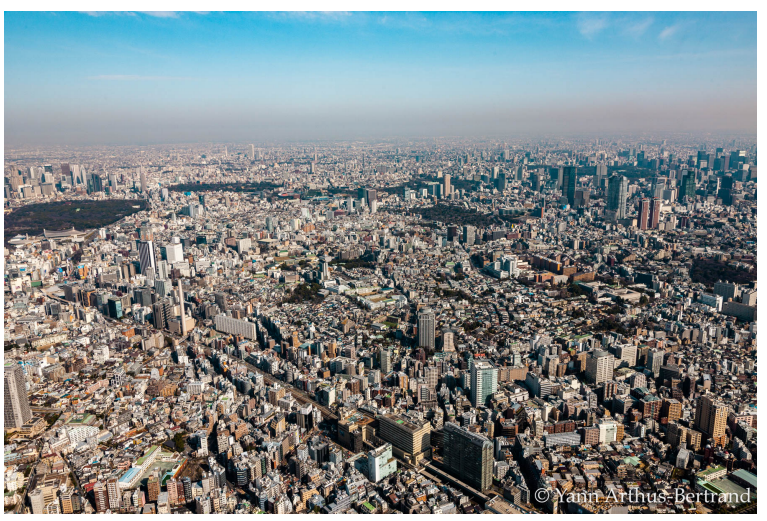

Figura 1. Tokyo, cidade com aproximadamente 40 milhões de pessoas. Autor: Yann Arthus-Bertrand. Fonte: <http:// www.yannarthusbertrand2.org/wp-content/uploads/ 2019/02/001-jp0903n-0636.jpg>. Acesso em: 23 abr. 2019.

1. Aproximadamente $46 \%$ da população (do mundo) vive com menos de US\$ 5,50/dia. Disponível em: $<$ https://www.worldbank.org/en/ news/press-release/2018/10/17/nearly-half-the-world-lives-on-lessthan-550-a-day>. Acesso em: 23 abr. 2019

usjt • arq.urb • número 27 | janeiro - abril de 2020
Afinal, o que significa ecologia urbana? A inspipiração para responder a essa indagação, ao longo deste trabalho, vem da asserção de Robert Smith (1980, apud McINTOSH, 1985, p. 8): "o que constitui ecologia "moderna" depende do ecologista ou do grupo de ecologistas a quem a pergunta é feita".

Dados recorrentes, incluindo os do Painel Intergovernamental de Mudanças Climáticas (Intergovernmental Panel on Climate Change (IPCC)), atestam que, desde os tempos pré-industriais, a temperatura da Terra elevou-se em média cerca de $10 \mathrm{C}$ com efeitos persistentes pelos próximos séculos ou milênios. Atualmente, o aumento médio da temperatura tem sido de $0,20 C$ por década, a partir do que se conclui que, em pouquíssimas décadas, entre 2030 e 2052, a elevação terá atingido alarmantes $1,50 \mathrm{C}$ acima do nível referencial. O impacto pode ser verdadeiramente preocupante nos diferentes ecossistemas conforme a localização geográfica, a infraestrutura instalada, a situação socioeconômica e a capacidade de resiliência do lugar, dentre diversas outras situações. Hoje, perto de
$54 \%$ da população vive em cidades, em um universo de aproximadamente 7,5 bilhões de pessoas. Estima-se que em 2050 dois terços dos habitantes estarão concentrados em áreas urbanas. Já existem quase três dezenas de cidades com mais de 10 milhões de habitantes, estando o maior contingente em Tokyo, na casa dos 40 milhões de pessoas (Figura 1). Essa situação torna-se particularmente grave, pois, segundo o Banco Mundial, metade desse contingente populacional vive em busca da satisfação apenas de suas necessidades básicas. ${ }^{1}$

O conceito de ecologia urbana tem se ampliado. As complexidades do mundo contemporâneo têm trazido efeitos e consequências para as diferentes escalas de cidades, em um universo de diversidade disciplinar que envolve relevantes questões qualitativas e quantitativas. É importante destacar que existem muitas publicações sobre ecossistemas urbanos a unidade funcional específica e prática - , mas há relativamente poucos textos sobre ecologia urbana. A possível relevância deste trabalho é colaborar para que haja uma discussão mais rica e aprofundada sobre o assunto, conformando uma 
2. O Protocolo de Montreal sobre "Substances that Deplete the Ozone Layer", um importante e reconhecido avanço da política ambiental, liderado pelas Nações Unidas, em 1987, identificou e condicionou a utilização de substâncias, principalmente clorofluorcarbonetos, que vinham exaurindo (depleting) a camada de ozônio, de forma absolutamente descontrolada.

usjt • arq.urb • número 27 | janeiro - abril de 2020 base teórica original.

\section{Contexto geral:}

Como introduzido anteriormente, no desafio involuntariamente proposto por Robert Smith, é lançado o objeto de referência desta pesquisa: afinal, o que significa ecologia urbana? Para responder a esta pergunta é apresentada uma (inquietante) base contextual de questões ecológicas contemporâneas nas cidades. A seguir, a partir de uma revisão bibliográfica, são trazidos diferentes conceitos, definições e justificativas de importantes autores relacionados ao tema em três momentos temporais: na gênese do uso da expressão (pré-conceito), no uso corrente da definição (conceito) e na análise crítica das ausências e presenças (pósconceito). Assim, além da apresentação de um certo compêndio teórico, são propostos alguns argumentos e raciocínios, de cunho (pretensamente) inovador, com o objetivo de consolidar perspectivas e contribuir para que esse campo disciplinar se desenvolva.

Segundo dados da Organização Mundial de Saúde (2014), em torno de $54 \%$ da população do mundo vive em áreas urbanas. As complexidades urbanas aumentam no embalo de densidades demográficas crescentes, da variedade de disciplinas e, principalmente, das possibilidades e interações combinatórias que ensejam. As resultantes são muitas: a degradação dos meios hídricos e atmosféricos, o esgotamento (deplection) da camada de ozônio ${ }^{2}$, a alteração dos ciclos biogeoquímicos, as mudanças nos padrões de precipitação pluviométrica, o aquecimento global, a impactante alteração dos fluxos de energia e matéria, a perda de biodiversidade e a eutrofização de lagoas são exemplos correntes que destacam a necessidade de se pensar os meios urbanos e naturais de forma sistêmica. Entretanto, a pegada ecológica talvez seja um dos principais problemas atuais. Algumas cidades, por exemplo, necessitam de dezenas de vezes de mais solo, além de seus limites territoriais, para prover seus recursos materiais e energéticos e receber suas disposições residuais: "Atualmente, a humanidade necessita da capacidade regenerativa de 1,5 planetas Terra para prover os serviços e bens que são demandados a cada ano" (WWF, 2014, p. 32).

O mais recente relatório do Painel Intergovernamental sobre Mudanças Climáticas (IPCC) que trata especificamente sobre aquecimento global, revisado em janeiro/2019, alerta para o caso de núcleos ou comunidades em situação de "risco desproporcionalmente" maior, como populações desfavorecidas, indígenas, dependentes de recursos agrícolas ou costeiros, além de regiões de risco como o Ártico, regiões insulares em desenvolvimento e países menos desenvolvidos, em função do aumento de $1,5^{\circ} \mathrm{C}$ da temperatura média do planeta. Há forte iminência do aumento de pobreza, além de maiores riscos à saúde, subsistência, segurança alimentar, 
3. Neste contexto, "práxis" significa a interação dialética entre teoria e prática, no que concerne aos sistemas sociais, culturais etc. Trata-se, em linhas gerais, de uma "prática pensada". Em função dos objetivos do presente trabalho, parece não caber aqui, desenvolver uma revisão bibliográfica do termo discorrer sobre a distinção entre práxis e poíesis, na obra de Aristóteles, ou do sentido desenvolvido por Karl Marx que identifica a práxis como uma ação humana de transformação da realidade social. 4. Lefebvre ao fazer esta distinção entre as expressões "cidade" e "urbano" procura destacar que as cidades são produtos sociais (com seus "elementos constituintes sua história"), com características bastante diversas (entre elas), e que pressupõem a existência sedentária de aglomerações de pessoas e estruturas (habitações, espaços de trocas, circulações etc.), ainda que alerte para a necessidade de um cuidado com uma "redução-extrapolação particularmente arbitrária e perigosa" da definição de cidade. Ou seja, um certo reducionismo excessivo que enxerga cidade como mero "centro de decisão e informação": "leva ao urbanismo dos canos, da limpeza pública, dos medidores, que se pretende impor em nome da ciência e do rigor científico" (LEFEBVRE, 2006, p.43). Lefebvre compara a cidade com uma "escrita" na relação direta com "os fenômenos urbanos" e afirma: "não posso separá-la nem daquilo que ela con- provimento de água etc. (IPCC, 2018, p. 11), com maiores efeitos nas cidades, principalmente de países não desenvolvidos.

Como destacado por Harvey Neo e C. P. Pow (2015), alguns enxergam a expressão "cidade sustentável" como um oximoro, pois, além dos detaIhes acima mencionados, são dependentes de regiões externas (rurais) para produção de energia e alimentos. Assim, o conceito de ecologia urbana surge como um campo disciplinar adequado para estudo de um quadro que envolve instabilidade, diversidade, dinamismo. As cidades possuem estruturas abertas que se caracterizam pela necessidade de adaptabilidade, interatividade e flexibilidade. Estes conceitos são menos rígidos e talvez mais coalescentes com a práxis ${ }^{3}$ das intrincadas cidades contemporâneas:

Talvez devêssemos introduzir aqui uma distinção entre a cidade, realidade presente, imediata, dado prático-sensível, arquitetônico - e por outro lado o "urbano", realidade social composta de relações a serem concebidas, construídas e reconstruídas pelo pensamento. Todavia, esta distinção se revela perigosa e a denominação proposta não é manejada sem riscos (LEFEBVRE ${ }^{4}, 1968-2006$, p. 49).

Emissões de poluentes não se restringem a delimitações políticas ou administrativas e se expandem por meio de fronteiras distantes, com impactos em inúmeros ecossistemas, por isso a distinção entre "ecologia das cidades" e "ecologia nas cidades":

Cidades são os principais contribuintes para o aquecimento global. De acordo com o UN Habitat, cidades consomem $78 \%$ da energia do mundo e produzem $60 \%$ das emissões de gases do efeito estufa. A despeito de ocuparem menos de $2 \%$ da superfície da Terra (NAÇÕES UNIDAS, 2018).

Possivelmente, um dos autores mais emblemáticos dos primórdios da ecologia como ciência, em tempos modernos, George Perkins Marsh, em seu livro Man and Nature (1864), publicado até hoje, "propunha que o mundo mantinha um estado de equilíbrio, exceto se alterado por ações do homem". Em tal publicação, o autor reconhece que o tema em questão - ecologia? - ainda não era uma disciplina formal (MARSH, 1864, p. 10), mas levantava questões em relação "às mudanças produzidas pela ação do homem nas condições da terra". Destacava, por exemplo, que "a equação da vida de animais e vegetais é um problema muito complicado para a inteligência humana resolver e nunca saberemos o quão largo será um círculo de interferência que produziremos na harmonia da natureza se jogarmos a menor pedra existente em um oceano de vida orgânica" (MARSH, 1864, p. 103).

Esta cisão entre natureza e homem desenha-se a partir do reconhecimento da "ideia de evolução: as formas naturais não tinham apenas constituição [física] mas uma história" (WILLIAMS, 1980, p. 73). 
tém nem daquilo que a contém, isolando-a como se fosse um sistema completo" (Ibidem, p.48) Completa ainda: "a cidade teve a singular capacidade de se apoderar de todas as significações a fim de dizê-las, a fim de escrevê-las (estipulá-las e "significá-las"), inclusive as significações oriundas do campo, da vida imediata, da religião e da ideologia política" (Ibidem, p.56). Assim: "a cidade depende também e não menos essencialmente das relações de imediatice, das relações diretas entre as pessoas e grupos que compõem a sociedade (famílias, corpos organizados, profissões e corporações etc.); ela não se reduz mais à organização dessas relações imediatas e diretas, nem suas metamorfoses se reduzem às mudanças nessas relações. Ela se situa num meio termo, a meio caminho entre aquilo que se chama de ordem próxima (relações dos indivíduos em grupos mais ou menos amplos, mais ou menos organizados e estruturados, relações desses grupos entre eles) e a ordem distante, a ordem da sociedade, regida por grandes e poderosas instituições (Igreja, Estado) por um código jurídico formalizado ou não, por uma "cultura" e por conjuntos significantes" (Ibidem, p.46)
História possível de ser entendida somente a partir das conclusões de Charles Darwin no século XIX. Esta dissociação ou distanciamento tão consolidado, até então, passa a ser revisto: "(...) ao se falar do homem "intervindo" nos processos naturais [era] de se supor que se [acreditava] que [era] possível não fazê-lo ou decidir não fazê-lo" (WILLIAMS, 1980 , p. 75). Um outro mito, amplamente questionado, mas, por vezes, ainda abordado nos meios ecológicos é o da sucessão ecológica como um processo determinista. Influenciado pelo reconhecido botânico Frederic Clements (1874-1945), um dos estudiosos pioneiros da ecologia, acreditou-se durante muito tempo que aquele conceito significava um desenvolvimento organizado e direcional que resultaria necessariamente em uma etapa final e permanente, ou seja, um ecossistema estabilizado (clímax). Hoje, esse pensamento não é válido para os meios essencialmente naturais e nem tampouco para os meios predominantemente urbanos

Há registros do uso pioneiro da expressão "ecologia", em 1800, pelo alemão Karl Friedrich Burdach (BARON, 1966; COLEMAN, 1977; FARBER, 1982 apud MCINTOSH, 1986, p. 2). Contudo, talvez o nome mais popular associado ao termo seja o do americano Henry David Thoreau, em 1858. Outros atribuem a Ernst Haeckel o uso do conceito, em 1866. Mais adiante, Roy Clapham (1930) parece dividir com Arthur George Tansley (1935) o uso pioneiro da expressão "ecossistema", como uma uni dade integrada de componentes físicos (abióticos) e biológicos (biocenoses) em um dado meio específico. Admite-se que nem sempre o resultado das intricadas relações que podem advir desta convivência biótica e abiótica resulta em justificativas rigidamente tangíveis. Acrescente-se que neste segmento físico-espacial, em definição de longa data, é prevista a interatividade de processos de fluxos de matéria e energia. Contemporaneamente, com o avanço da tecnologia da informática, não parece descabido complementar a definição de ecologia, particularmente do tipo urbano, com o acréscimo da ideia de tráfego de comunicação e informação" (MIYAMOTO, 2018). Novos entes interdisciplinares desafiam a compreensão estrita do tema e demandam outras perspectivas analíticas.

O entendimento sobre o tema em si não é novo, mas a premência do quadro evidencia a importância de se privilegiarem os fatos e contextos provenientes das zonas urbanas. Na realidade, desde a Revolução Industrial (considerada a pioneira), em meados do século XVIII, alicerçada no aperfeiçoamento da máquina a vapor por James Watts e com inovadores métodos de produção e gerenciamento fabril, há a compreensão histórica de que o mundo já atravessou outras Revoluções Industriais. A Segunda Revolução Industrial, por exemplo, foi baseada na eletricidade que possibilitou a invenção de inúmeros equipamentos e eletrodomésticos, iluminação pública mais eficiente etc. e, posteriormente, 
5. Existem depressões em zonas de encontro entre placas tectônicas, nas profundezas mais longínquas dos mares (cerca de 8.000 a 11.000 metros), as chamadas fossas abissais ou oceânicas, onde se avalia que não exista ainda influência antrópica. Embora, em 2017, já tenha sido constatada a presença de Poluentes Orgânicos Persistentes (POP) nas fossas abissais das Marianas e de Kermadec (JAMIESON et al., 2017).

usjt • arq.urb • número 27 | janeiro - abril de 2020 como uso do petróleo e a produção industrial em massa - principalmente dos automóveis, - transformou as paisagens urbanas. A Terceira Revolução Industrial, após a Segunda Guerra Mundial, foi fundamentada na eletrônica, novas formas de telecomunicação e automações industriais. Hoje, considera-se que a Quarta Revolução Industrial fundamenta-se na inteligência artificial, na biotecnologia, na nanotecnologia, nas redes de comunicação e nas transações globais, em novos padrões de comportamento de consumo, comportamento, gestão etc.

Cada um desses momentos trouxe referências de vivência, convívio, comunicação e gerenciamento diferentes. As configurações das cidades foram se modificando e novos tipos de interações foram naturalmente se flexibilizando e se adaptando às novidades tecnológicas e urbanas. Por isso, entendese por que a ecologia urbana assumiu diferentes perspectivas e gradativa importância, ao longo de tempos relativamente recentes, e consolida-se como uma ciência presente em diversos segmentos. Derivada do campo disciplinar da biologia, ecologia era simplesmente descrita como "estudo de organismos e seus habitats". Uma disseminada conceituação sobre ecologia ainda é:

O estudo científico de processos que influenciam a distribuição e a abundância de organismos, as relações entre organismos, e as interações entre (estes) organismos e a transforma- ção e o fluxo de energia e matéria (LIKENS, 1992, apud McDONNELL, 2013, p. 6).

Evidentemente, os limites e abrangências do tema da ecologia urbana devem ser tratados com ponderação. Como todo assunto atinente aos sistemas complexos, deve ser reconhecido como um processo interativo e não um fim em si mesmo. Derivam desse pensamento duas premissas importantes. A primeira é que natureza e seres humanos não podem estar em trincheiras adversárias. A segunda é que "as cidades, precisamente devido às densidades e diversidades de suas populações humanas, são também lugares onde as soluções devem ser desenvolvidas" (NIEMELÄ, 2011).

Também é consensual que não parece haver muitos locais no planeta que não sofram (ou tenham sofrido) efeitos de cunho antrópico ${ }^{5}$. O amadurecimento do termo deu-se por algumas passagens importantes, mas, certamente, baseado nos avanços (e possíveis retrocessos) inerentes às invenções e descobertas tecnológicas, a partir do século XVIII, e nos consequentes métodos e rigores da pesquisa científica. A visualização e o entendimento das origens da expressão devem ser buscados em diversos campos disciplinares, dentre os quais: "história da paisagem, história do meio ambiente, história da geografia, arqueologia ambiental, história das florestas ou história da ecologia" (SZABÓ, 2014). Há ainda referências à bionomia ou mesmo entendimentos de que a ecologia era um braço da fisiologia ou 
ainda da biologia:

A expressão ecologia e a emergência da ecologia como uma ciência reconhecida são claramente produtos do último terço do século XIX. Diversos ecologistas e historiadores convergiram para ecologia como uma lógica (...) consequente do pensamento Darwiniano da evolução e [por considerar] Charles Darwin como o primeiro ecologista (MCINTOSH, 1985, p. 15).

Cristopher Alexander publicou, na revista Architectural Forum, em 1965, o notório artigo Uma cidade não é uma árvore. Nele, há um questionamento da concepção (extrema) do racionalismo modernista relativo às cidades planejadas, justificada, quase paradoxalmente, por meio de diagramas e análises combinatórias de cunho matemático. A relativa simplicidade associada a uma árvore - "não uma verde e com folhas, [mas] (...) uma estrutura abstrata" - é confrontada com uma estrutura mais rebuscada, com conjuntos e subconjuntos, com dinâmicas cinéticas que possibilitam arranjos infinitos e quase sempre imprevisíveis, chamadas de "semitrama" ou "semi-retícula". Segundo o autor, as cidades "artificiais" são mais próximas da árvore e as "naturais" - construídas gradativamente pelas muitas camadas interdisciplinares, temporais e multiautorais - são mais próximas da "semi-trama". Assim, é possível indagar: quais são as variáveis importantes no universo da ecologia urbana? Que interações existem entre elas?

\section{Conceitos:}

Endlicher define ecologia urbana de duas formas:

a) "no contexto das ciências naturais, ecologia urbana refere-se a padrões biológicos e processos ambientais associados em áreas urbanas como uma subdisciplina da biologia e da ecologia (...)"; b) "contudo, a segunda e complementar definição implica na perspectiva antropocêntrica. Aqui, ecologia urbana é entendida como uma abordagem multidisciplinar para melhorar as condições de vida da população das cidades, referentes às funções ecológicas dos habitats urbanos ou ecossistemas para pessoas (...)" (SUKOPP; WITTING, 1998, apud ENDLICHER et al., 2007, p. 1).

Ironicamente, pode-se afirmar que a cisão entre natureza e sociedade (seres humanos) foi "amplamente" superada. Ressalte-se, talvez por um perigoso motivo. É praticamente impossível se estudar a natureza plena sem que se considerem as causas e efeitos (frequentemente nocivos e deletérios) de caráter antropogênico, mesmo nos recônditos mais longínquos. Assim, essa variável impõe-se como parte de uma equação, porém, a capacidade de o ser humano em intervir no planeta expôs fragilidades latentes:

O homem interfere nos ecossistemas da Terra em níveis extraordinários através da conversão do solo e dos recursos de consumo, alteração de 
6. Para melhor compreensão do contexto do uso do conceito de mecanosfera, além da nota de rodapé $\mathrm{n}^{\circ}$ - 8 , específica sobre o tema, transcreve-se uma parte maior do texto: "O princípio particular à ecologia ambiental é o de que tudo é possível tanto as piores catástrofes quanto as evoluções flexíveis. Cada vez mais, os equilíbrios naturais dependerão das intervenções humanas. Um tempo virá em que será necessário empreender imensos programas para regular as relações entre o oxigênio, o ozônio e o gás carbônico na atmosfera terrestre. Poderíamos perfeitamente requalificar a ecologia ambiental de ecologia maquínica já que, tanto do lado do cosmos quanto das práxis humanas, a questão é sempre a de máquinas - e eu ousaria até dizer de máquinas de guerra. Desde sempre a "natureza" esteve em guerra contra a vida! Mas a aceleração dos "progressos" técnico-científicos conjugada ao enorme crescimento demográfico faz com que se deva empreender, sem tardar, uma espécie de corrida para dominar mecanosfera" (GUATTARI, 1990, p.52).

usjt • arq.urb • número 27 | janeiro - abril de 2020 habitats e composição de espécies, descontinuidade de processos hidrológicos e modificação do fluxo de energia e dos ciclos de nutrientes (ALBERTI, 2003).

Dessa forma, em pesquisa, desenvolvida por Richard Fuller e Katherine Irvine, dedicada às interações entre homem e natureza, em que se constata que "apesar do evidente empobrecimento do ambiente natural nos meios urbanos, ou talvez por causa disso, muitos habitantes das cidades buscam interação com a natureza de alguma forma" (FULLER; IRVINE, 2010, p. 134). Os pesquisadores chegam a uma interessante conclusão: a partir de um questionário sobre visitas a parques urbanos, a despeito de $59 \%$ dos consultados em Guangzhou, China, terem respondido que os acessam "frequentemente" ou "muito frequentemente" e, no Reino Unido, outros 92\% terem afirmado frequência (aos parques urbanos), a urbanização tem isolado progressivamente pessoas do ambiente natural, na medida em que as cidades crescem e tornam-se mais densas (FULLER; IRVINE, 2010, p. 135). Em um alerta feito em 1990, em que destacava as "três ecologias" - a do meio ambiente, a das relações sociais e a da subjetividade humana, - Guattari (1990, p. 25) dizia ${ }^{6}$.

Mais do que nunca natureza não pode ser separada da cultura e precisamos aprender a pensar transversalmente as interações entre ecossistemas, mecanosfera e universos de referências sociais e individuais.
Alberti et al. (2003) convida a uma reflexão sobre como se apresentam os seres humanos e os padrões ecológicos a partir da interação entre processos socioeconômicos e biofísicos, já que a condição urbana é multidimensional e altamente variável no tempo e no espaço. Atualmente, admite-se que questões ambientais, climáticas, culturais, econômicas, etárias, estruturais, geográficas, históricas, ideológicas, políticas, religiosas, sexuais, sociais etc. entrelaçam-se e conferem nuanças específicas em contextos urbanos variados (LEIS, 2004).

Scarano, por exemplo, utiliza uma interessante estratégia de representação, por intermédio de uma metáfora apoiada no filósofo Mario Bunge, para explicar a questão da sustentabilidade em que destaca as expressões: "emergência", "submergência" e "convergência" nas estruturas ecológicas. Segundo ele:

Sustentabilidade emerge como uma novidade a partir da convergência entre linhas independentes de pesquisa, como sociologia, economia e ecologia no corpo da ciência e a partir da tensão entre ambientalismo e desenvolvimento como movimentos sociais ou ideologias. Também é relacionada com a emergência de uma nova ética baseada em uma justiça intergeracional. A convergência da sustentabilidade como ciência, como política e como valor moral, por sua vez, implica na submergência ou até mesmo o desaparecimento do antigo (SCARANO, 2018). 
7. Hoje, as distinções entre meio rural e meio urbano, - outrora simplificadas pela dicotomia "agricultura" e "indústria" respectivamente, demandam justificativas e definições mais complexas. De um lado, há um meio rural com variadas atividades não agropecuárias (turismo rural e toda a estrutura que propicia e demanda; artesanato; indústria de alimentos; emergência do setor terciário atrelado ao ensino, administração etc.), mecanização de alta tecnologia, produções e operações baseadas em estudos cientíicos, valorização das questões ecológicas e aumento de fluxos de matérias e energias, por exemplo. Por outro lado, as crescentes fricções de cunho socioeconômico, os refugiados, os fluxos migratórios, as alternativas contemporâneas de moradias, as formas de ocupação periurbana e mesmo o interesse pelos sistemas ecológicos, incluindo parques, pomares, florestas, reservas urbanas etc., resultam na configuração de um meio urbano também híbrido. Sem deixar de lembrar que os fluxos crescentes de pessoas, bens e serviços fazem parte da conexão entre os dois meios (já não tão facilmente distinguíveis): no "continuum urbano-rural" (UN, 2016, p.18).

usjt • arq.urb • número 27 | janeiro - abril de 2020
Assim, há vários sentidos de "emergência" envolvidos. A partir da questão ética, do entendimento de sustentabilidade, da alternância de novos paradigmas de política e conceito etc. No sentido de "submergência", revela-se um embate entre a "tradicional" e a "nova" ciência da conservação (preservação). De um lado e de outro há ressalvas e objeções sobre aspectos conceituais que significam a alternância de posturas. A princípio, o valor ético e moral e a assunção da elevada valorização da natureza dos "tradicionalistas" cederiam lugar ao bem-estar humano - antropocentrismo - conjugado com uma ênfase relativa da proteção da biodiversidade como defendem os "novos conservacionistas". Por fim, o significado de "convergência" implicaria na combinação de aproximações (abordagens) e dos diferentes campos disciplinares.

Acrescente-se ainda a ideia de "divergência" (da fonte original formulada por Bunge) - não considerada por Scarano - que poderia ser entendida como a reorganização da energia e da matéria, causada pelo embate de posicionamentos antagônicos (ou não convergentes) que dessa forma podem resultar em situações, muitas vezes positivas, no tocante ao conceito de sustentabilidade.

O mesmo autor destaca a premissa de valor moral no conceito de sustentabilidade. Vale lembrar que desde a publicação de o Homem e a biosfera (1971), aperfeiçoada pelo "relatório Brundtland"
(1987) — ambos de iniciativa das Nações Unidas —, há essa preocupação com as gerações presentes e futuras (intergeracional) e a equidade nacional (ricos e pobres) e internacional (países desenvolvidos/poluidores e países subdesenvolvidos).

Deve-se compreender que, por muito tempo, um cenário que ilustrava o embate entre os proprietários dos meios de produção e o proletariado serviu para justificar desigualdades da sociedade e até mesmo a configuração espacial das cidades. Conceitos até certo ponto triviais ${ }^{7}$, explicavam as centralidades, as formas de ocupação geográfica, migrações e muitas outras expressões atinentes ao âmbito do urbanismo. Contudo, "muitas outras contradições transcendem esta lógica” (CUNHA, 2012), em bases amplas e diversificadas, sejam concernentes a aspectos negativos, como em relação ao preconceito, à intolerância, à leniência, à violência etc., ou positivos, em relação a formas criativas de compartilhamento de usos e de bens, à otimização de recursos tecnológicos, a novas formas de comunicação e prestação de serviços etc.

Seria ingênuo não (tentar) enxergar grandes interesses obscuros quando se trata de um tema que pressupõe convivências e imbricações. Afinal, a priori, o planeta é essencialmente desigual e plural. $\mathrm{O}$ conceito de ecologia urbana política, na busca de justiça ambiental e social, deve estar especialmente baseado no "entendimento dos diferentes acessos 
8. Quando Guattari menciona a expressão "mecanosfera" não necessariamente ser refere a produ tos mecânicos, mas também a questões sociais, comunitárias, psicológicas, culturais e familiares, dentre diversos outros temas, atinentes a relações sociais e subjetivas do mundo contemporâneo. paralelo com uma máquina, no sentido mais simples e corrente do termo, - "um instrumento ou engenho que transforma energia e/ou utilizar essa transformação para produzir determinada ação ou efeito", - é porque peças (fragmentos) quando reunidas e montadas, passam a fazer parte de algo mais complexo, adquirem uma articulação que pode transformar contex tos, comportamentos, situações etc. A alta tecnologia, a inteligência artificial, a biotecnologia, a nanotecnologia, os novos padrões de comunicação, os desafios da arte e da cultura etc. acontecem em um mundo de desigualdades, tensões e fragmentações políticas que proporá novas interpretações para campos disciplinares diretamente relacionados com identidades, segurança, poder e liberdade (social e individual).

usjt • arq.urb • número 27 | janeiro - abril de 2020 aos recursos e benefícios ambientais, assim como à forma como a degradação ambiental desproporcionalmente afeta grupos sociais marginalizados" (NEO; POW, 2015).

Guattari abordava questões que se mostram, hoje, fundamentais, pois considerava diversos segmentos desafortunados da sociedade, relações esgarçadas e ainda comentava:

Cada vez mais, os equilíbrios naturais dependerão das intervenções humanas. Um tempo virá em que será necessário empreender imensos programas para regular as relações entre o oxigênio, o ozônio e o gás carbônico na atmosfera terrestre (GUATTARI, 1990, p. 52).

O mesmo autor, em uma visão bastante abrangente da sociedade e seus problemas ambientais, em um contexto complexo do mundo capitalista em sua fúria de produção e consumo, completa ${ }^{8}$ :

Desde sempre a "natureza" esteve em guerra contra a vida! Mas a aceleração dos "progressos" técnico-científicos conjugada ao enorme crescimento demográfico faz com que se deva empreender, sem tardar, uma espécie de corrida para dominar a mecanosfera (GUATTARI, 1990, p. 52).

Em síntese, é possível falar de uma crise identitária de um planeta. Quanto mais evolui do ponto de vista científico, mais longeva passa a ser a vida hu- mana e mais dinâmico torna-se o cotidiano, porém mais massacrante impõem-se as demandas e as expectativas:

Não haverá verdadeira resposta à crise ecológica a não ser em escala planetária e com a condição de que se opere uma autêntica revolução política, social e cultural reorientando os objetivos da produção de bens materiais e imateriais. Essa revolução deverá concernir, portanto, não só às relações de forças visíveis em grande escala mas também aos domínios moleculares de sensibilidade, de inteligência e de desejo. Uma finalidade do trabalho social regulada de maneira unívoca por uma economia de lucro e por relações de poder só pode, no momento, levar a dramáticos impasses (...) (GUATTARI,1990, p. 9).

Mohamed M. Mostafa desenvolveu estudo de particular interesse, a partir de uma preocupação ambiental principal: o aquecimento global e suas resultantes. No trabalho, compara quarenta nações em padrões relacionados à emissão de $\mathrm{CO}_{2}$, tendências pós-materialistas, religiosidade, orientação política e controle local. O autor destaca a inadequação de pesquisas exclusivamente realizadas em países com características tão díspares como EUA, Korea, Turquia e Egito, por exemplo, e propõe o acesso a características em âmbito individual - "porque a preocupação ambiental é baseada nas motivações e cognições dos indivíduos de uma sociedade", além do nível dos países. Três hipóteses teóricas ancoram o estudo: a) o novo paradigma político: maior preocupação ambiental dos cidadãos, na medida 
em que determinados países tornam-se mais ricos; b) o paradigma das condições objetivas: problemas ambientais experimentados pelos indivíduos tornam previsíveis suas preocupações com o problema (ambiental); c) o paradigma baseado nos valores: envolvimentos religiosos ou com o controle do lugar podem impactar a consciência em relação a temas ambientais.

De acordo com as conclusões da investigação, Mostafa relata que o argumento - frequente e notoriamente utilizado por Richard Inglehart, nos anos 1980, dentre outros autores, - de que "países ricos com altos níveis de valores pós-materialistas tendem a se voltar mais para a qualidade ambiental" não se sustenta, pois países menos desenvolvidos possuem preocupações semelhantes. De acordo com o estudo, o paradigma objetivo das experiências individuais não é suficiente para se aferir um compromisso com a causa ambiental, pois deve se levar em conta uma investigação mais ampla que inclui contextos diversos, múltiplos níveis de análises e estudos de casos. Além disso, valores religiosos podem ser positivos para a questão ecológica, pois lidam com questões éticas e culturais importantes que podem incentivar comportamentos altruístas e ambientais.

A ecologia política, campo disciplinar surgido na década de 1970, por diferentes autores de origens múltiplas, propõe-se a lidar com "relações de poder social e a formação e o funcionamento das ecologias e das paisagens", segundo Dianne Rocheleau (apud PAULSON; GEZON, 2004, p. 17). Miranda utiliza conceitos desenvolvidos pelo sociólogo alemão Norbert Elias para lidar com as relações de poder e interdependência social para "o entendimento dos conflitos e processos de mudanças ambientais ligados à apropriação do espaço e seus recursos". Ele conclui que "mudança ambiental e os processos de territorialização são equivalentes, pois refletem transformações nas relações entre sociedades e naturezas" (MIRANDA, 2013, p. 143-144).

De forma a não estender excessivamente o tema, toma-se de empréstimo a contribuição objetiva e didática de Eduardo Gudynas (2014). O ambientalista uruguaio estabelece uma classificação importante, após uma ampla revisão bibliográfica, na qual define três campos, nos quais considera inclusive aportes latino-americanos:

a) Interacionistas: corrente com raízes acadêmicas, sobretudo aquelas manifestações originadas no hemisfério Norte. Surgem a partir das influências da ecologia cultural, na década de 1970, e da antropologia ecológica desenvolvida na década de 1960. Dedicam-se à análise das interações entre sociedade e meio ambiente, com distinção entre situações contextuais diferentes.
Guattarri é um dos pioneiros desta visão. 
b) Normativistas: baseiam suas práticas no "conjunto de normas, objetivos, ações etc. entendidas como uma agenda política orientada às questões ambientais frequentemente voltadas para ideologias políticas" e ações sociais, por meio de um partido verde, ONGs ou movimentos sociais, a partir dos quais se lançam ao debate público, à gestão ambiental, ao planejamento territorial etc.

c) Politólogos: analisam "atores, processos e implicações das questões ambientais como parte das chamadas 'ciências políticas"'. Aferem "desempenhos dos partidos verdes, a postura dos partidos políticos convencionais diante dos temas ambientais". Possuem preocupação também com a "participação e informação cidadã", no ambiente democrático.

No campo da ecologia política merece distinção também a situação dos refugiados. Um problema da mais alta gravidade que necessita ser enfrentado. Dados das Nações Unidas, em 2017, revelam que 68,5 milhões de pessoas (quase $1 \%$ da população do planeta), estão deslocadas de suas origens, por força de guerras, violência e perseguições, em números que avançam na proporção de 44,5 mil pessoas a cada dia. Aproximadamente dois terços de todos os refugiados do mundo são provenientes de apenas cinco países: Síria (6,3 miIhões), Afeganistão (2,6 milhões), Sudão do Sul (2,4 milhões), Myanmar (1,2 milhões) e Somália (986 mil). Além disso, 52\% do contingente de refu- giados são crianças e jovens (com menos de 18 anos) (UNHCR, 2017).

Outra perspectiva relacionada ao tema da ecologia urbana é relacionada à ecologia industrial. Na distinção entre fontes móveis (veículos) e fontes fixas (fábricas), no que concerne à poluição atmosférica, deve se levar em conta as indústrias, usinas termoelétricas e incineradores de resíduos como os maiores contribuintes (dentre as fontes fixas). Os efluentes líquidos industriais, da mesma forma que os domésticos, devem ser tratados para que, a despeito dos processos industriais, incluindo águas de refrigeração, águas pluviais e esgoto doméstico, sejam lançados nas redes com padrões biológicos, físicoquímicos etc. adequados. Além disso, os resíduos sólidos devem ser encarados sob o conceito da "lógica reversa":

Ao buscar uma semelhança com os ecossistemas naturais, a ecologia industrial propõe a mudança do padrão linear para o padrão cíclico de produção, em que as saídas dos sistemas produtivos não sejam descartadas, mas sejam entradas de outros processos produtivos. Admitem-se ainda sistemas intermediários que processem os outputs em inputs para sistema seguinte da rede (SOUSA, 2018, p. 163).

Também não é possível deixar de considerar, nesta revisão bibliográfica, o campo da ecologia da paisagem. Embora cunhado pelo geógrafo alemão Carl Troll, em 1939, a expressão ganhou maior visibilida- 
9. (...) "mosaico de paisagens: movimentos de água, nutrientes, propágulos, animais e outros materiais" (WU, Jianguo. Landscape Ecology. Disponivel em: <https:// www.researchgate.net/publication/ 278708397 Landscape Ecology>

Acesso em: 24 abr. 2019)

10. Vale destacar também: Declaração Universal dos Direitos Humanos, artigo 25, 1948: "Todo o homem tem direito a um padrão de vida capaz de assegurar a si $e$ a sua família saúde e bem estar, inclusive alimentação, vestuário, habitação, cuidados médicos e os serviços sociais indispensáveis, e direito à segurança em caso de desemprego, doença, invalidez, viuvez, velhice ou outros casos de perda de meios de subsistência em circunstâncias fora de seu controle".

usjt • arq.urb • número 27 | janeiro - abril de 2020 de nos anos da década de 1980 e 1990, quando preocupações ambientais se transformaram em centralidades de pesquisa. Trata-se de uma ciência que lida com a interação de padrões espaciais — na realidade, mosaicos de paisagens ${ }^{9}$ — na relação direta com processos ecológicos que, por considerarem diferentes escalas (física e temporal) e campos disciplinares, resultam em uma grande heterogeneidade espacial e temporal. Influenciada pela geografia, biologia e ciências sociais, pressupõe, evidentemente, a presença de fluxos de matéria e energia:

devem ser coibidas, em um estado democrático de direito, sendo assegurados "os direitos e as liberdades proclamados na (...) Declaração [Universal dos Direitos Humanos], sem distinção alguma, nomeadamente de raça, de cor, de sexo, de língua, de religião, de opinião política ou outra, de origem nacional ou social, de fortuna, de nascimento ou de qualquer outra situação" (NU, Artigo $\left.2^{\circ}, 1948\right)$. Mas não é isso que acontece em significativas partes do planeta. $^{10}$

Em convergência com a ideia de convivência, interatividade e solidariedade, vale destacar outro viés do tema proposto, o da ecologia humana, diretamente associada à construção do pensamento, da sociabilidade e do sentido crítico individual e coletivo. Particularmente, para os fins deste trabalho, deve ser destacado tudo aquilo que, em diferentes escalas (microssistema, messosistema, exossistema e macrossistema), conforme proposto por Urie Bronfenbrenner, conduz ao desenvolvimento humano ao longo do tempo de sua existência e do tempo histórico de seu ambiente (cronossistema) e, portanto, mostra-se diretamente vinculado à educação ambiental:

Objetivamente, depois da recorrência a muitos raciocínios, conjecturas e citações, pretende-se contribuir com algumas considerações críticas. Durante as pesquisas, por poucas vezes, houve uma explícita referência a um campo disciplinar de extraordinária relevância, no contexto da ecologia urbana: a socioecologia. As dimensões discriminatórias
Pode-se afirmar que a ecologia e a bioecologia do desenvolvimento humano também propõe uma educação que desloca o ser humano da posição de onipotência antropocêntrica para integrar a posição de componente do todo, configurado como espaço psicológico ou espaço vital pelos objetos, pessoas e acontecimentos aos 
quais a pessoa atribui significado (YUNES; JULIANO, 2010, p. 368)

Aliás, deve ser destacado que, em publicações dedicadas à ecologia urbana no bojo dos fatos, consequências e medidas preventivas, raramente há menção ao tema da educação ambiental, exceto em segmentos específicos - quase nunca conjugada em um mesmo texto que aborde questões mais gerais como ecologia ou mais específicas como ecossistemas, por exemplo. Afinadas com o pensamento de Guattari, anteriormente exposto, na crítica aos objetivos da produção de bens materiais e imateriais e da necessidade de comprometimento do ser humano com as questões ambientais, as autoras destacam:

A educação ambiental compromete-se a responder a desequilíbrios e desacomodações, pois visa criar uma lógica que abarque um modelo de ser humano que supere o modelo de desenvolvimento social e econômico vigente. Trata-se de uma área de conhecimentos que propõe a formação de pessoas capazes de enfrentar criticamente a exploração desenfreada e conseqüente degradação ambiental que engloba a exploração e exaurimento da humanidade (YUNERS; JULIANO, 2010, p. 369).

Embora discutido ao longo do texto, talvez seja importante resgatar, com mais ênfase, outro sentido de conexão nos meios urbanos. Essa é uma expressão que sugere vínculos e apropriações com repercussões inclusive na forma urbana, em ciclos virtuosos ou viciosos com características, muitas vezes, profundas e longevas. A expressão pode ser entendida em relação: aos vínculos funcionais ou afetivos; às percepções e interpretações individuais e coletivas; aos deslocamentos físicos pedonais ou veiculares; aos instrumentos de infraestrutura (instalações e estrutura viária); às escalas de transição das cidades (locais, regionais, metropolitanas, exurbanas) etc. Por espelhamento, é possível pensar nos territórios como unidades funcionais fundamentais da ecologia urbana: "o território é entendido como substrato/palco para efetivação da vida humana, sinônimo de solo/terra e outras condições naturais, fundamentais a todos os povos" (SAQUET, 2007, p. 31). As relações dos sistemas sociais, por meio das vertentes da cultura, política ou economia, por exemplo, moldam estruturas de poder, no espaço geográfico, por intermédio da construção histórica e coletiva. Ou seja, são ecossistemas que vão se configurando, por meio de alianças e embates, por meio de dinâmicas sociais. Nas cidades, diferentemente dos contextos naturais, há certos componentes materiais (bens), sociais e psicológicos que as tornam particularmente complexas, como revela Saskia Sassen (2009): "[em cidades ou grandes sociedades], elementos não-científicos são partes cruciais do quadro: questões de poder, pobreza e diferenças ideológicas e preferências culturais são partes da pergunta e da resposta". 
Mais específico ainda é considerar que:

São as forças produtivas e as relações de produção, na expansão do capitalismo, que configuram o território. Essa organização é mediada por relações políticas, que envolvem os conflitos oriundos das relações capital-trabalho. O território, num primeiro plano, é um produto socialmente organizado e, num segundo, é condição para a valorização do capital (SAQUET, 2007, p. 70).

Por fim, é pouco provável que algumas visões de relevantes intelectuais alcancem realidades tão desiguais de países em desenvolvimento. Em tese, Gregotti, por exemplo, estaria absolutamente correto:

A cidade induz o indivíduo a considerar-se centro de uma situação, protagonista, de certo modo direto, de uma dinâmica de desenvolvimento, e considerar-se (...) habitante de um ponto do território privilegiado e dono dos significados que representa para o grupo social (GREGOTTI, 1975, p. 69).

A anomia presente em determinados lugares, do ponto de vista da ecologia urbana, para o bem ou para o mal, é geradora de variáveis que justificam plenamente o conceito de ecologia, de acordo com a pesquisa aqui desenvolvida. Contudo, poderes paralelos, fragilidades institucionais, educação deficiente, infraestrutura precária, desequilíbrios socioeconômicos etc. criam instabilidades políticas e sociais graves.

\section{Considerações finais}

Fatores biofísicos, normalmente, são determinantes iniciais de apropriações, comportamentos, deslocamentos, cerimônias festivas e religiosas, hábitos alimentares, engenhosidades técnicas etc. Além disso, condições climáticas por demais severas podem inibir ocupações, assim como a presença de água, principalmente potável, pode incentivar assentamentos. Evidentemente, cada um destes elementos implica em um resultado de cunho antropológico ou social diferente que pode resultar em uma conformação físico-espacial inesperada. Iniciativas históricas, com caráter ideológico, também são capazes de configurar fragmentos ou conjuntos peculiares, seja pelas fricções previstas entre forças produtivas (produção, circulação, distribuição e consumo) de níveis distintos que reverberam na espacialidade urbana, seja pela indução do desenvolvimento local ou regional.

Parece ser consensual que o planeta atravessa a Quarta Revolução Industrial, baseada na inteligência artificial, nanotecnologia, criptografia, biotecnologia etc., com novas formas de operações, gestões e governanças digitais.

Junto com o esgotamento da prevalência produtiva associada à indústria, novas matrizes tecnológicas trouxeram formas inovadoras de gestão e, com elas, outras opções de consumo e comportamento, 
pelo menos para uma (pequena) parcela da população. Principalmente, em meio urbano, recursos computacionais poderão auxiliar na prevenção de sinistros, otimizar funcionamentos, agilizar processos e criar sinergias. Da mesma forma que no século XVIII não existiam palavras como "indústria", "ferrovia" e "liberalismo". Atualmente, "inteligência artificial", "time sharing" ("compartilhamento de tempo") e "neoliberalismo" são expressões consolidadas, representantes de modelos de gestão e causa/efeito de complexidades contemporâneas.

Ao mesmo tempo, as Nações Unidas lançaram, em 2015, os Objetivos do Desenvolvimento Sustentável (ODS), em número de dezessete (objetivos) replicados em 169 metas, que buscam a redução da pobreza, dos desequilíbrios, das injustiças etc. As contradições do mundo contemporâneo talvez possam estar ilustradas pelos números também fornecidos pelas Nações Unidas, em 2013, que apontavam que 6 bilhões de pessoas tinham acesso a celulares e apenas 4,5 bilhões tinham acesso a banheiros em funcionamento. Assim, ao mesmo tempo em que severos problemas sociais e ambientais vão surgindo e afetando a vida no planeta, a população avoluma-se e adensa-se, a longevidade aumenta e as abrangências das ações humanas estendem-se.

Como visto, cada sistema dispõe de suas variáveis específicas com subsistemas particulares. Esses

subsistemas, ao se complexificarem e adquirirem relativa autonomia, transformam-se em novos sistemas. Que processos interativos serão possíveis? Quais providências tornarão mais eficientes os fluxos de matéria, energia e informação? Quais medidas estancarão a geração de resíduos, a descarga de efluentes poluentes, a emissão atmosférica prejudicial e a consequente destruição de vidas? Quais sistemas tornarão os convívios mais inclusivos? Enfim, fica a pergunta final: doravante, quais direcionamentos e parâmetros nortearão a ecologia urbana, em um mundo tão complexo, instável e desigual? 


\section{Referências}

ALBERTI, Marina et al. Integrating humans into ecology: Opportunities and challenges for studying urban ecosystems. BioScience, v. 53, n. 12, p. 1.169-1.179, 2016. Disponível em: <http://bioscience.oxfordjournals.org/content/53/12/1169.abstract>. Acesso em: 5 out. 2016.

ALEXANDER, Christopher. The city is not a tree. Architectural Forum, v. 122, n. 1/2, p. 58-62, 1965. Parte I, parte II.

CUNHA, José Ricardo. Os direitos sociais vistos de uma perspectiva humanística ou sobre por que estamos diante de uma questão ética de primeira grandeza. In: TOLEDO, Cláudia (org.). Direitos sociais em debate. Rio de Janeiro: Elsevier, 2012. v. 1, p. 91-126.

CUSHMAN, Samuel; EVANS, Jeffrey; McGARIGAL, Kevin. Landscape ecology: Past, present, and future. In: CUSHMAN, Samuel; HUETTMANN, F. (ed.) Spatial complexity, informatics and wildlife conservation. 2010. cap. 4, Springer.

ENDLICHER, Wilfried et al. Urban ecology - Definitions and concepts, shrinking cities: Effects on urban ecology and challenges for urban development, [s.l.], [s.n.], 2007. Disponível em: <https://
www.researchgate.net/publication/232906753_Urban Ecology - Definitions and Concepts>.

Acesso em: 18 abr. 2019.

ESCOBAR, Arturo. Steps to an antiessentialist political ecology. Current Anthropology, Wenner-Gren Foundation for Anthropological Research, University of Chicago, Chicago, v. 40, n. 1, 1999.

FULLER, Richard; IRVINE, Katherine N. Interactions between people and nature in urban environments. In: GASTON, Kevin (ed.). Urban ecology. New York: Cambridge University Press, 2010. p. 134-171.

GREGOTTI, Vittorio. Território da arquitetura. São Paulo: Editora Perspectiva S.A., 1975.

GUATTARI, Félix. As três ecologias. 11. ed. Campinas, São Paulo: Papirus, 1990.

GUDYNAS, Eduardo. Ecologias Políticas - Ideas preliminares sobre concepciones, tendências, renovaciones y opciones latinoamericanas. Centro Latino Americano de Ecología Social (CLAES), 2014. Disponível em: <https://www.academia.edu/ 8985240/Ecolog\%C3\%ADas_Pol

\%C3\%ADticas._Concepciones tendencias renovaciones_y opciones_Latinoamericanas>. Acesso em: 24 abr. 2019. 
HOBSBAWN, Eric. A era dos extremos. 2. ed. São Paulo: Companhia das Letras, 1995.

IPCC, Global Warming of $1.5^{\circ} \mathrm{C}$. An IPCC special report on the impacts of global warming of $1.5^{\circ} \mathrm{C}$ above pre-industrial levels and related global greenhouse gas emission pathways, in the context of strengthening the global response to the threat of climate change, sustainable development, and efforts to eradicate poverty, 2018. Disponível em: $<$ https://www.ipcc.ch/site/assets/uploads/sites/ 2/2018/07/

SR15 SPM version stand alone LR.pdf>. Acesso em: 19 abr. 2019

JAMIESON, Alan, MALKOCS, Tamas, PIERTNEY, Stuart et al. Bioaccumulation of persistent organic pollutants in the deepest ocean fauna. Nature Ecology \& Evolution, 1, 0051, 2017.

KEELER, M.; BURKE, B. Fundamentos de projeto de edificações sustentáveis. Porto Alegre: Bookman, 2010.

KÖCK, Günter; GRABHERR, Georg. 40 years of the UNESCO man and the biosphere programme. Austria. Eco.mont, v. 6, n. 1, 2014. Disponível em: $<$ https://en.unesco.org/news/fileadmin/MULTIMEDIA/HQ/SC/pdf/editorial_G-Kock_mab_austria.pdf>. Acesso em: 5 out. 2016
LEFEBVRE, Henry. O direito à cidade. 4. ed. São Paulo: Centauro Editora, [1968] 2006.

LEIS, Héctor Ricardo. A modernidade insustentável. As críticas do ambientalismo à sociedade contemporânea. Centro Latino Americano de Ecologia Social, 2004. Disponível em: <www.ecologiaurbana.net>. Acesso em: 20 out. 2016.

LOWENTHAL, David. Nature and morality from George Perkins Marsh to the Millennium. Journal of Historical Geography, v. 26, n.1, p. 3-27, 2000. Disponivel em: <http://geography.fullerton.edu/taylor/ ENST595T/Lowenthal_JHG.pdf>. Acesso em: 5 nov. 2016.

MARQUET, Pablo et al. On theory in ecology. Bioscience, v. 64, p. 701-710, 2014.

MARSH, G. Perkins. Man and nature. Nova York: Charles Scribner, 1864. Disponível em: <https://archive.org/details/manandnatureorp00marsgoog>. Acesso em: 6 nov. 2016.

MARSH, G. Perkins. Man and nature. Cambridge, Massachusetts: The Belknap Press of Harvard University Press, [1864] 1965a.

McDONNELL, Mark. The history of urban ecology. An ecologist's perspective. In: NIEMELÄ, J. et 
al (ed.). Urban Ecology: patterns, processes and applications. Oxford: Oxford University Press, 2011.

McINTOSH, Robert. The background of ecology: Concepts and theory. Cambridge: Cambridge University Press, 1986.

MELOSI, Martin. V. The historical dimension of urban ecology: Frameworks and concepts. In: BERKOWITZ, A. et. al. Understanding urban ecosystems: A new frontier for science \& education. New York: Springer-Verlag, 2002.

MIRANDA, Roberto de Sousa. Ecologia política e processos de territorialização. Revista Sociedade e Estado, v. 28, n. 1, janeiro/abril 2013.

MOSTAFA, Mohamed. Post-materialism, religiosity, political orientation, locus of control and concern for global warming: A multilevel analysis across 40 nations. Springer Netherlands, 2015. Disponível em: $<$ https://springer.proxy.ufrj.br/article/10.1007/ s11205-015-1079-2\#Sec1>. Acesso em: 20 abr 2019.

MIYAMOTO, James. Ecologia urbana: um panorama global e local. Enanparq, 2018.

MUMFORD, Lewis. A cidade na história: suas origens, transformações e perspectivas. 5. ed. São Paulo: Livraria Martins Fontes, 2008.
NEO, H.; POW, C. P. Eco-cities and the promise of social environmental justice. In: BRYANT, R. (ed.). The international handbook of political ecology. Cheltenham, Reino Unido: Edward Elgar Publishing Limited, 2015. p. 401-412.

NIEMELÄ, Jari. Urban ecology - Patterns, process, and applications. New York: Oxford University Press, 2011.

PAULSON, Susan; GEZON, Lisa; WATTS, Michael. Politics, ecologies, genealogies. In: PAULSON, Susan; GEZON, Lisa (ed.). Political ecology across spaces, scales and social groups. New Jersey: Rutgers University Press, The State University of New Jersey, 2004.

ROBBINS, Paul. (ed.). Encyclopedia of environment and society. Los Angeles: Sage Publication, 2007.

SAQUET, Marcos Aurélio. Abordagens e concepções de território. São Paulo: Editora Expressão Popular, 2007.

SASSEN, Saskia. Bridging the ecologies of cities 
and of nature. In: THE 4TH INTERNATIONAL FORUM ON URBANISM (IFOU): THE NEW URBAN QUESTION - URBANISM BEYOND NEO-LIBERALISM. Delft, 2009. Disponível em: <http://portal.unesco.org/es/files/ 46764/12562292491Bridging_ecologogies Sassen.pdf/Bridging\%2Becologogies\%2BSassen.pdf>. Acesso em: 1 fev. 2019.

SCHWAB, Klaus. Shaping the Fourth Industrial Revolution. Geneve: World Economic Forum, 2018.

SOUSA, Luiz Henrique dos Santos Silva. Ecologia industrial: evolução histórica e produção científica. In: DZIEDZIC, Maurício. Revista Brasileira de Ciências Ambientais. Associação Brasileira de Engenharia Sanitária e Ambiental (ABES), dezembro/ 2018. n. 50.

SZABÓ, Péter. Historical ecology: Past, present and future. Cambridge Philosophical Society. Biological Reviews, n. 90, p. 997-1.014, 2014.

THOREAU, Henry David. A desobediência civil. Penguin Companhia (e-book), 1849-2012.

UNESCO/UNEP. Programme on man and the biosphere (MAB). MAB report series, Paris, n. 22, 1974.
UNHCR. Global Trends - Forced displacement in 2017, 2017. Disponível em: <https://www.unhcr.org/5b27be547>. Acesso em: 19 abr. 2019.

UNITED NATIONS. Nova Agenda Urbana, 2016. Disponível em: <http://habitat3.org/wp-content/uploads/NUA-Portuguese-Angola.pdf>. Acesso em: 02 mar. 2020.

UNITED NATIONS. Climate Action, 2018. Disponível em: <https://www.un.org/en/climatechange/cities-pollution.shtml>. Acesso em: 23 abr. 2019.

VON ZUBEN, Cláudio. História da ecologia: o trabaIho pioneiro de Eugen Warming no Brasil e na Europa. Revista Biociência, Taubaté, v. 11, n. 3-4, p. 160-163, jul./dez. 2005.

WILLIAMS, Raymond. Ideas of nature. In: WILLIAMS, Raymond (ed.). Problems in materialism and culture. Londres: Verso, 1980. p. 67-85.

YUNES, Maria Angela Mattar; JULIANO, Maria Cristina. A bioecologia do desenvolvimento humano e suas interfaces com educação ambiental. Cadernos de Educação - FaE/PPGE/UFPel, Pelotas, RS, p. 347-379, 2010. 
WWF. Living planet - Report 2014, Species and spaces, people and places, 2014. Disponível em: <https://www.wwf.or.jp/activities/data/ WWF_LPR_2014.pdf>. Acesso em: 18 abr. 2019.

$<$ http://ec.europa.eu/environment/integration/research/newsalert/pdf/179na4_en.pdf>. Acesso em: 23 out. 2018.

$<$ http://www.un.org/esa/population/publications/sixbillion/sixbilpart1.pdf>. Acesso em: 23 out. 2018.

$<$ https://www.un.org/en/climatechange/cities-pollution.shtml>. Acesso em: 19 abr. 2019. 